\title{
Assessment of Oxaliplatin-induced Chronic Neuropathy and Anticancer Efficacy Through Pharmacokinetic and Toxicodynamic Evaluation of a Rat Model of Colorectal Cancer
}

\author{
YUKAKO ITO, SHINJI KOBUCHI, WAKI TAKESADA and CHIHARU TAKAHASHI \\ Department of Pharmacokinetics, Kyoto Pharmaceutical University, Kyoto, Japan
}

\begin{abstract}
Background/Aim: Oxaliplatin-induced chronic neuropathy is a prominent factor for dose reduction and not completing all cycles of chemotherapy for patients with colorectal cancer (CRC). The aim of the study was to investigate the pharmacokinetics and toxicodynamics of oxaliplatin-induced chronic neuropathy in CRC rats to ensure effective management. Materials and Methods: A rat model of CRC was developed using 1,2-Dimethylhydrazine and dextran sulfate. Oxaliplatin (L-OHP) was administered intravenously to CRC rats every week. The pharmacokinetic profiles and tumor distribution of L-OHP and chronic neuropathies were investigated for over four weeks. Results: The mean values of the area under the concentration-time curve for L-OHP showed a dose-dependent increase. Chronic neuropathy occurred from Day 14 in the $8 \mathrm{mg} / \mathrm{kg}$ group and Day 19 in the 3 and $5 \mathrm{mg} / \mathrm{kg}$ groups. Conclusion: These results provide preliminary information for the development of a pharmacokinetic and toxicodynamic model of L-OHP for CRC therapy cycles.
\end{abstract}

Oxaliplatin (L-OHP) is often used for the treatment of metastatic colorectal cancer as adjuvant therapy in combination with 5-fluorouracil $(5-\mathrm{FU})(1,2)$. However, peripheral neuropathy is a dose-limiting adverse effect of L-OHP. This peripheral neuropathy may be acute or chronic (3). The onset of acute oxaliplatin-induced neuropathy usually occurs within 1-2 days after administration, and patients experience a strong sensitivity to cold sensations. Oxaliplatininduced chronic neuropathy includes dysesthesias and

Correspondence to: Yukako Ito, Ph.D., Department of Pharmacokinetics, Kyoto Pharmaceutical University, Yamashina-ku, Kyoto, 607-8412, Japan. Tel: +81 755954626, Fax: +81 755956311, e-mail: yukako@mb.kyoto-phu.ac.jp

Key Words: Oxaliplatin (L-OHP), chronic neuropathy, tumor shrinkage, pharmacokinetic, toxicodynamic, colorectal cancer rat model. paresthesias of the extremities, similar to those observed with cisplatin and paclitaxel (4).

Oxaliplatin-induced neuropathy is a prominent factor for reduction of dose and withdrawal period and the discontinuation of therapy. Therefore, strategies to prevent these problems can increase the efficacy and tolerability of regimens containing L-OHP. Two different approaches, a stop-and-go method; and the use of neuromodulatory agents, such as antiepileptics, or calcium and magnesium infusions are considered. However, neither approach is sufficiently efficient $(5,6)$.

Chronic neuropathy is irreversible and the symptoms, dysesthesias and paresthesia of the extremities, do not resolve quickly. Therefore, to prevent these conditions, the oxaliplatin dose schedule must be optimized. Chronic neuropathy, the result of the accumulation of oxaliplatin over the course of prolonged treatment, results in lack of sensory perception and is associated with painful sensations $(7,8)$. L-OHP treatment results in inhibition of neurite outgrowth, (9-11) and selective atrophy of a specific population of dorsal root ganglion neurons (12). Our previous study has indicated an association between the pharmacokinetic profile of L-OHP, oxaliplatin-induced neuropathy, and the hematological profile of normal rats (13). However, it is important to use a pathological animal model for the evaluation of clinical translational medicine approaches, including pharmacokinetics, pharmacodynamics, efficacy, and safety.

For patients with colorectal cancer, the main goal is to continue the treatment cycles, thereby retaining anticancer efficacy. In this study, the relationship between the pharmacokinetic profile including tumor distribution of L-OHP and chronic neuropathy and antitumor efficacy were evaluated in a rat model of colorectal cancer.

\section{Materials and Methods}

Materials. Elplat ${ }^{\circledR}$ (L-OHP) was purchased from Yakult Honsha Co., Ltd. L-OHP was obtained from Wako Pure Chemical Industries Ltd. (Osaka, Japan). Male Wistar rats were obtained from Japan SLC Inc. (Hamamatsu, Japan) and fed a standard solid-meal 
Table I. Pharmacokinetic parameters of $\mathrm{L}-\mathrm{OHP}$

\begin{tabular}{|c|c|c|c|c|c|c|}
\hline \multirow[t]{2}{*}{ Pharmacokinetic parameters } & \multicolumn{2}{|c|}{$3 \mathrm{mg} / \mathrm{kg}$} & \multicolumn{2}{|c|}{$5 \mathrm{mg} / \mathrm{kg}$} & \multicolumn{2}{|c|}{$8 \mathrm{mg} / \mathrm{kg}$} \\
\hline & Day 1 & Day 22 & Day 1 & Day 22 & Day 1 & Day 22 \\
\hline$t_{1 / 2}(h)$ & $0.6 \pm 0.2$ & $2.1 \pm 1.6$ & $0.5 \pm 0.4$ & $0.3 \pm 0.3$ & $0.4 \pm 0.3$ & $0.5 \pm 0.1$ \\
\hline CL $(1 / \mathrm{h} / \mathrm{kg})$ & $2.6 \pm 1.8$ & $1.2 \pm 0.5$ & $1.6 \pm 1.0$ & $2.5 \pm 1.9$ & $2.0 \pm 1.9$ & $2.0 \pm 1.3$ \\
\hline $\mathrm{Vd}(1 / \mathrm{kg})$ & $2.0 \pm 0.7$ & $3.1 \pm 1.3$ & $0.8 \pm 0.5$ & $0.7 \pm 0.3$ & $0.9 \pm 0.7$ & $1.4 \pm 0.6$ \\
\hline $\operatorname{AUC}_{0 \rightarrow \infty}(\mu \mathrm{g} * \mathrm{~h} / \mathrm{ml})$ & $1.5 \pm 0.7$ & $2.8 \pm 1.3$ & $3.8 \pm 1.7$ & $3.8 \pm 3.7$ & $7.7 \pm 5.3$ & $5.2 \pm 2.5$ \\
\hline
\end{tabular}

Mean \pm S.D. $(\mathrm{N}=4-6)$.

commercial diet (LabDiet; Nousan Corp., Yokohama, Japan). All other materials were of reagent grade and were used as received.

Colorectal cancer rat model. The rat model of colorectal cancer was established by using a rapid induction method (14). In total, 24 10week-old male Wistar rats were administered 1,2-dimethylhydrazine $(40 \mathrm{mg} / \mathrm{kg})$ once a week and were supplied with drinking water containing $1.0 \%$ dextran sulfate sodium solution ad libitum for 2 weeks. The rats were housed in a room with a controlled environment: a 12-h light/dark cycle, ambient temperature of $23^{\circ} \mathrm{C} \pm 2{ }^{\circ} \mathrm{C}$, and humidity of $50 \% \pm 10 \%$. The rats were given free access to drinking water and were fed a moderate-fat basal diet (Oriental Yeast Co., Ltd., Tokyo, Japan). After 10 weeks, aberrant crypt foci (ACF) were observed by using an endoscope (AVS AEC1, OLYMPUS. Co. Ltd, Tokyo, Japan). The body temperature of the colorectal cancer rat model was maintained at $37^{\circ} \mathrm{C}$ during experimental procedures. An aliquot of $0.25 \mathrm{ml}$ of blood was withdrawn from the left femoral vein and plasma samples were collected after centrifugation of blood at $20,630 \mathrm{~g}$ for $15 \mathrm{~min}$ at $4^{\circ} \mathrm{C}$ (KUBOTA 3700; Kubota Corp., Tokyo, Japan).

Pharmacokinetic study of L-OHP in rat colorectal cancer model. LOHP $(100 \mathrm{mg})$ was added in $20 \mathrm{ml}$ of saline and used for intravenous injection. Male Wistar colorectal model rats $(306 \pm 10 \mathrm{~g}$ in mass) were anesthetized by isoflurane $(2 \%)$ before the administration of the L-OHP solution (at $3.0,5.0$, or $8.0 \mathrm{mg} / \mathrm{kg}$ ). LOHP was administered once a week over 4 weeks (i.e., on Days 1 , 8,15 , and 22). Each test group consisted of 4 to 6 rats. After the first and fourth administration (Day 1 and 22), blood samples were withdrawn from the right jugular vein at $3,5,10,20,30,45,60,90$, and $120 \mathrm{~min}$. The temperature of the rats was kept at $37^{\circ} \mathrm{C}$ within the experiment. Plasma samples were kept at $-80^{\circ} \mathrm{C}$ until use. All experiments were conducted in accordance with the Guidelines for Animal Experimentation, Kyoto Pharmaceutical University.

Von Frey test for mechanical allodynia. Chronic neuropathy was evaluated by using von Frey test for mechanical allodynia. Neuropathy was evaluated by the up-down method of the von Frey filament test. The rats were left in Plexiglas boxes $(20 \times 20 \mathrm{~cm})$, which were constructed using a metallic mesh floor, and left to acclimate to their environment for $15 \mathrm{~min}$. Von Frey filaments including $0.6,1,1.4,2,4,6,8,10,15$, and $26 \mathrm{~g}$, were attached to each hind paw for $4 \mathrm{sec}$, and the withdrawal responses were observed. First, stimuli using $8 \mathrm{~g}$ filaments were applied. Once a withdrawal response to the filament was obtained, a weaker stimulation was applied by thinner filament. This procedure was repeated until monofilament stimuli did not induce a behavioral response. When no response to filament stimuli was obtained, stronger stimuli were applied using thicker monofilaments. The weakest stimulus causing a positive response was set as the threshold value. The stimuli were applied to each anterior paw for a $5 \mathrm{~s}$ period. The measurements were repeated five times, and the final value was calculated by averaging these measurements (15, 16). The threshold value was determined every 3 or 4 days after the first application.

Tumor tissue resection and body weight loss measurement in colorectal cancer rat model. After the fourth treatment on Day 22, whole tumor tissues of the colon were isolated. Tumor volume was calculated using the following formula: $0.5 \times($ length $) \times(\text { width })^{2}$. To evaluate the tumor tissue distribution of L-OHP, the tumors were surgically resected. After blood collection, tumor tissues were collected and washed with $1 \mathrm{ml}$ PBS to remove blood contamination, dried briefly, transferred to $2 \mathrm{ml}$ centrifugation tubes, and stored at $-80^{\circ} \mathrm{C}$. Prior to analysis, frozen tissues were thawed at room temperature $\left(25^{\circ} \mathrm{C}\right)$, weighed, and homogenized in 4-volumes of PBS by using a tissue homogenizer (Polytoron PT-10-35-GT, Kinematica AG, Switzerland) operated at 24,000 rpm. L-OHP concentrations in the homogenized samples were analyzed by using the extraction method described in our previous report (13). The body weight of the rats was recorded each week and was considered as a systemic parameter indicative of toxicity.

Analysis of L-OHP. L-OHP was analyzed by liquid chromatography/ tandem mass spectrometry (LC-MS/MS), according to the report by Minakata et al. (17). Standard samples were prepared for the quantification of L-OHP in plasma. One hundred microliters of plasma (or $90 \mu \mathrm{l}$ of blank matrix and $10 \mu \mathrm{l}$ of standard solution) and $200 \mu \mathrm{l}$ of acetonitrile, added to deproteinize, were vortex mixed and centrifuged at 13,000 rpm for 5 min (KUBOTA 3700; Kubota Corp., Tokyo, Japan). The supernatant $(100 \mu \mathrm{l})$ was mixed with an equal volume of $5 \mathrm{mM}$ ammonium formate buffer ( $\mathrm{pH} 3.0$ ) and $20 \mu \mathrm{l}$ of $1.0 \mathrm{M}$ diethyldithiocarbamate solution for $3 \mathrm{~min}$ at room temperature. One milliliter of isoamyl alcohol was then added to extract L-OHP. After centrifugation at 13,000 rpm for $5 \mathrm{~min}, 100$ $\mu \mathrm{l}$ of the supernatant was mixed with $10 \mu \mathrm{l}$ of $1.0 \mathrm{M}$ oxalic acid. A $100 \mu \mathrm{l}$ aliquot was transferred into a vial, and $20 \mu \mathrm{l}$ were injected into LC-MS/MS instrument. The standard curve for L-OHP in plasma was obtained using a range of 0.1 to $250 \mu \mathrm{g} / \mathrm{ml}$. These values were presented as platinum $(\mathrm{Pt})$ amount, which includes the Pt related metabolites. Chromatographic analysis was constructed by a high-performance LC system (SHIMADZU, Kyoto, Japan) with an API 3200 mass spectrometer (Applied Biosystems/MDS Sciex, Foster City, CA, USA). L-OHP was detected by using the 


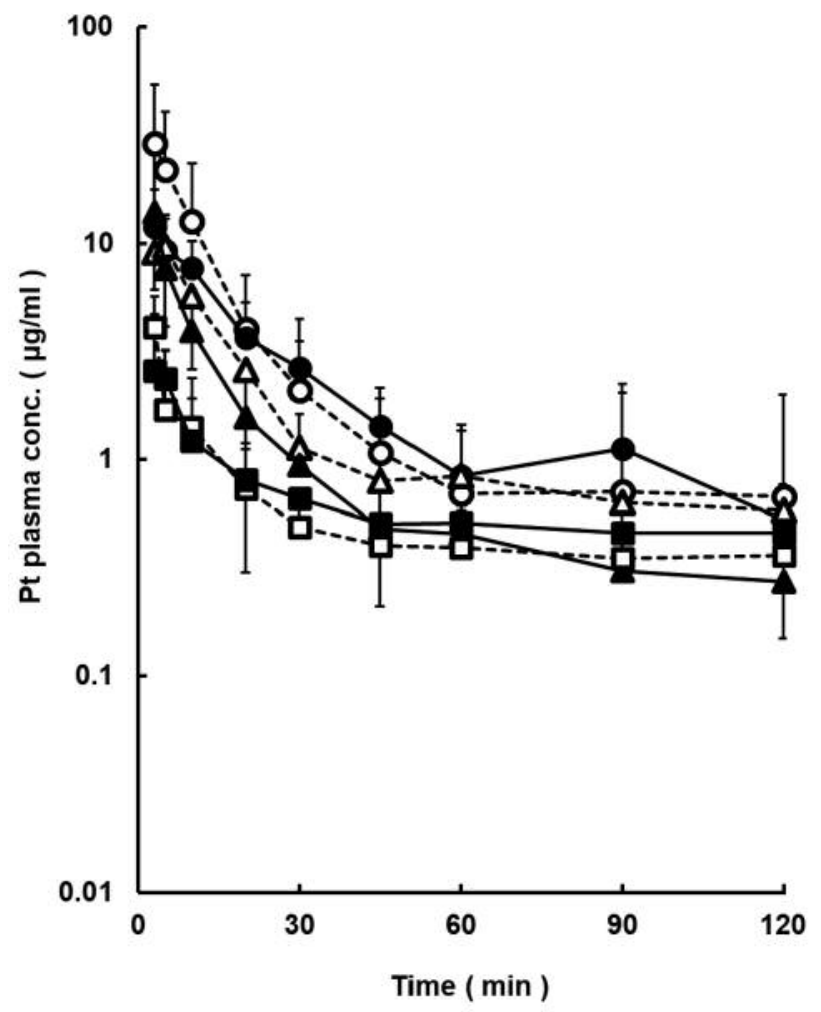

Figure 1. Plasma concentration-time curve of L-OHP, on Day 1 and 22 after intravenous injection of 3.0, 5.0, and $8.0 \mathrm{mg} / \mathrm{kg}$ doses in colorectal cancer rats. Open symbols and dotted lines refer to Day 1 and closed symbols and solid lines refer to Day 22. The administered doses of 3.0, 5.0 and $8.0 \mathrm{mg} / \mathrm{kg}$, are shown as squares, triangles, and circles, respectively. Each point represents the mean $\pm S . D$. of four experiments.

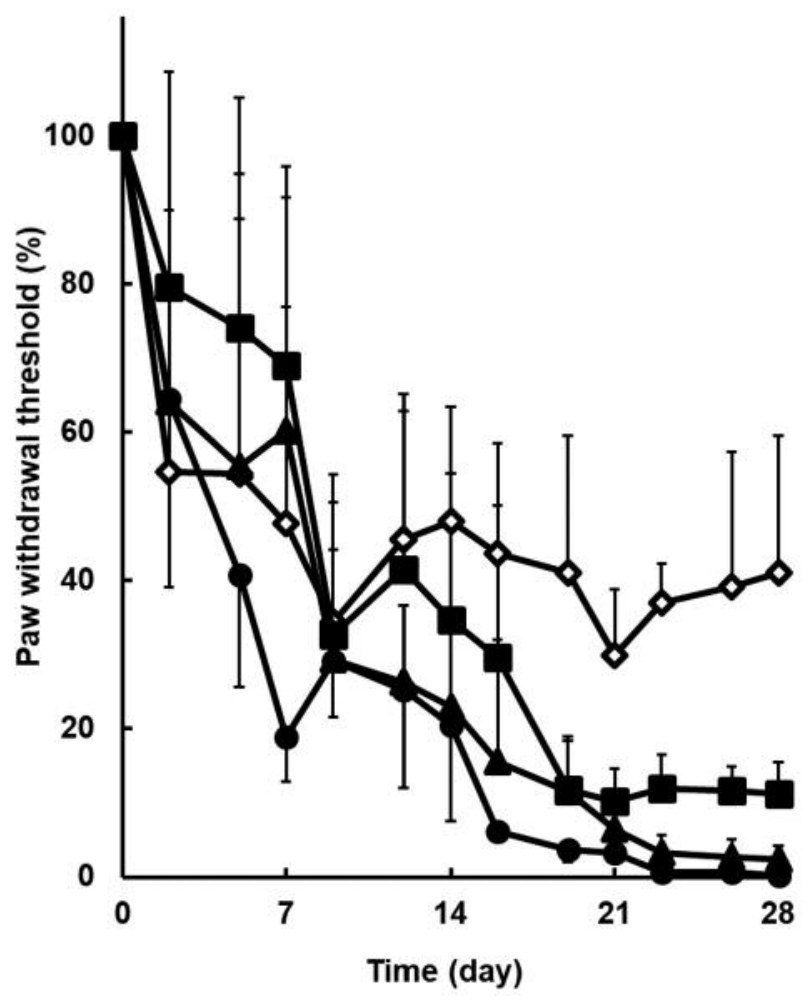

Figure 2. L-OHP-induced mechanical allodynia was assessed as paw withdrawal thresholds in colorectal rats after the administration of 3.0 $(\mathbf{\square}), 5.0(\mathbf{\Delta})$, and $8.0(\bullet) \mathrm{mg} / \mathrm{kg}$ doses, and control $(\diamond)$. Each point shows the mean $\pm S . D$. of four experiments.

were significantly higher than those on Day $1(p<0.05)$ for all doses. The volume of distribution was increased with repeated administration of L-OHP. However, there were no significant differences in $\mathrm{AUC}_{0-\infty}$ or the volumes of distribution. This suggests that the tumor tissue distribution of L-OHP contributed to this phenomenon.

L-OHP-induced chronic neuropathy. L-OHP-induced mechanical allodynia was observed by using the von Frey test for a chronic neuropathy, as shown in Figure 2. The percentage of the withdrawal threshold compared to initial levels was calculated from the results of the von Frey test. After the third administration, mechanical allodynia occurred in all groups except the control group. In particular, on Day 14, neuropathy was observed in the $8 \mathrm{mg} / \mathrm{kg}$ group, as shown by a significant reduction in the withdrawal threshold, unlike in the control group. On Day 19, neuropathy onset occurred in the 3 and 5 $\mathrm{mg} / \mathrm{kg}$ dose groups, and the withdrawal threshold decreased by $11.7 \% \pm 6.7 \%$ and $11.5 \% \pm 7.5 \%$, respectively. After treatment, the desensitized condition was observed as a response to 


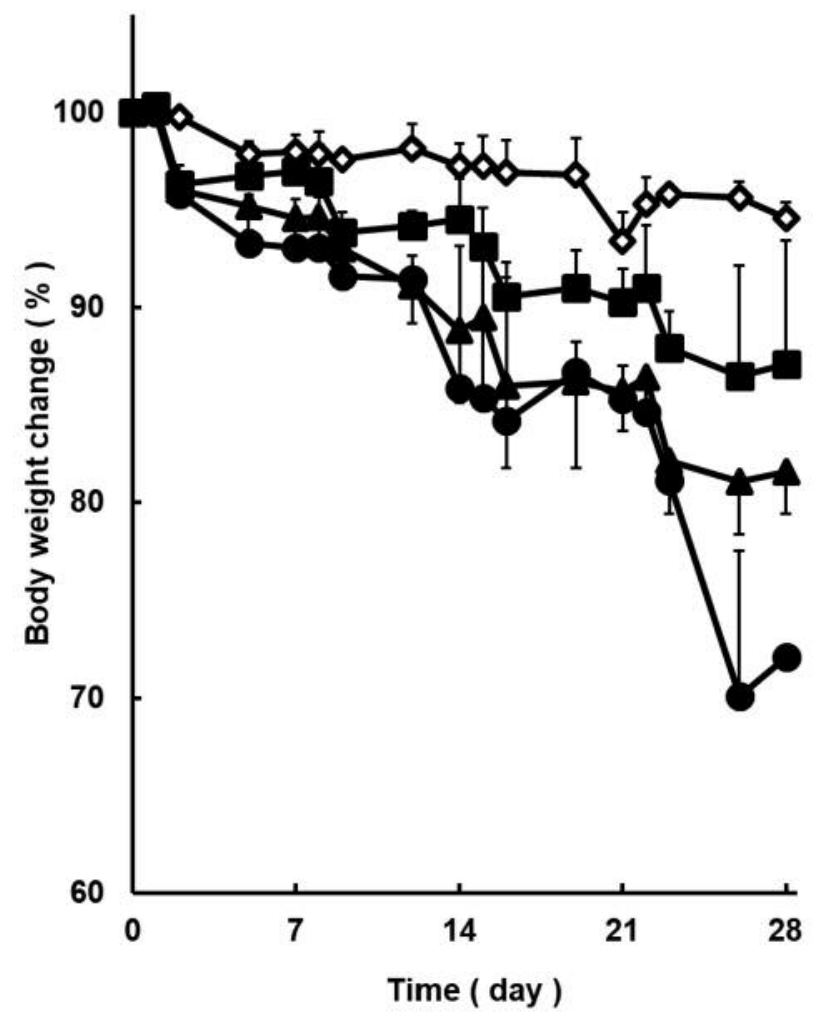

Figure 3. Body weight loss in colorectal cancer rats after the treatment of L-OHP once per week at the doses of $3.0(\mathbf{\square}), 5.0(\mathbf{\Delta})$, and $8.0(\bullet) \mathrm{mg} / \mathrm{kg}$, and control $(\diamond)$. Each point shows the mean \pm S.D. of four experiments.

mechanical stimuli. Especially on Day 28, a significant decrease in the threshold percentage, compared to that in the control group, at $11.1 \pm 4.3 \%(3 \mathrm{mg} / \mathrm{kg}), 2.3 \pm 1.9 \%(5 \mathrm{mg} / \mathrm{kg})$ and $0.3 \pm 0.0 \%(8 \mathrm{mg} / \mathrm{kg})$, respectively. These results suggested that the sensitivity to L-OHP-induced neuropathy was depended on the administered dose (18). Multiple dose administration was shown to increase the incidence of L-OHPinduced chronic neuropathy.

Body weight loss after multiple dose administration of $L$ $O H P$. The weight loss in the colorectal cancer model rats is shown in Figure 3. On Day 14, body weight in the groups of 5 and $8 \mathrm{mg} / \mathrm{kg}$ was significantly decreased compared to the $3 \mathrm{mg} / \mathrm{kg}$ group. This was the result of toxicity from L-OHP. Body weight in the control group and the $3 \mathrm{mg} / \mathrm{kg}$ group decreased by less than $15 \%$ compared with the initial weight.

Tumor tissue distribution of L-OHP. After the fourth treatment with L-OHP, tumor tissues were resected from the colorectal cancer regions. The tumor volumes were $215.9 \pm 49.1,170.4 \pm 20.8,120.2 \pm 28.2$, and $37.2 \pm 15.0 \mathrm{~mm}^{3}$ in
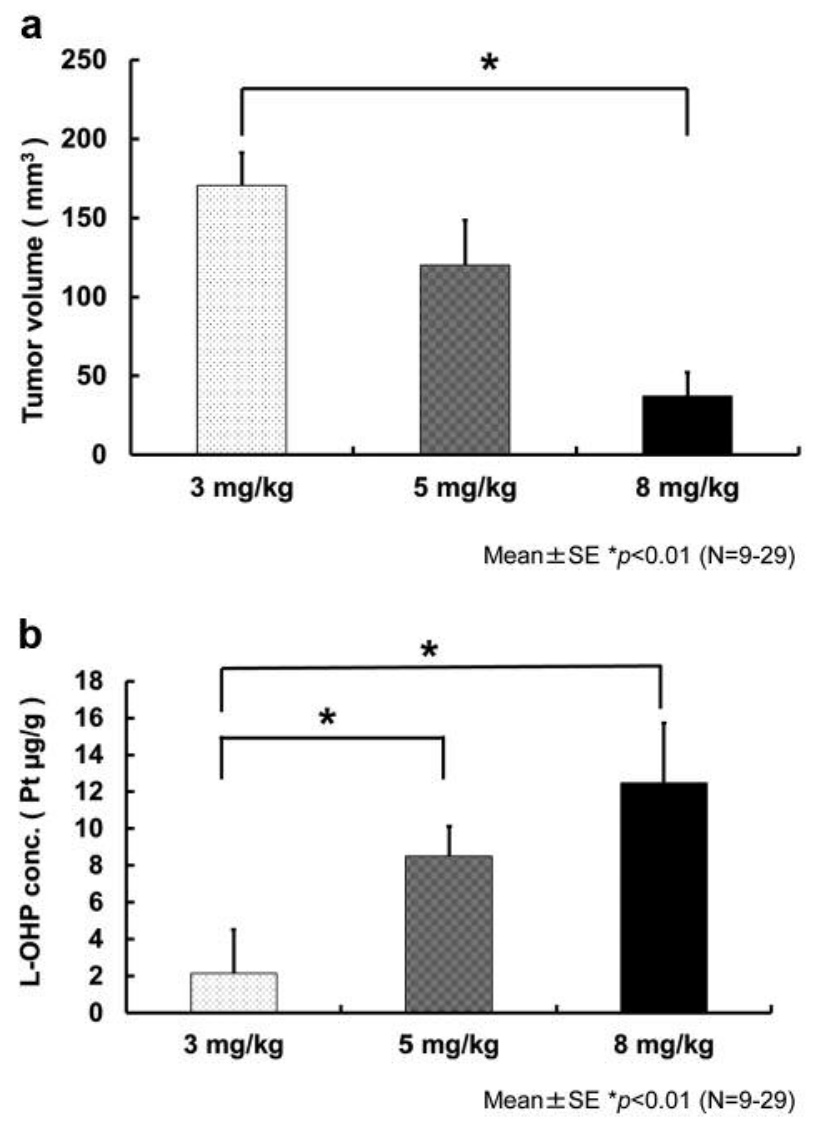

Figure 4. Tumor volume (a) and tumor concentration (b) of L-OHP in colorectal cancer rats after treatment of L-OHP once weekly at the administered doses of control (white bar), 3.0 (grey bar), 5.0 (dark bar), and 8.0 (black bar) $\mathrm{mg} / \mathrm{kg} \mathrm{L-OHP}$. Each point represents the mean \pm S.D. of two of four experiments.

the control, 3, 5, and $8 \mathrm{mg} / \mathrm{kg}$ groups, respectively, as shown in Figure 4. Moreover, the concentration of L-OHP in the tumor tissue was $2.2 \pm 0.3,8.5 \pm 1.6$, and $12.5 \pm 3.3 \mathrm{Pt} \mu \mathrm{g} / \mathrm{g}$ in the 3,5 , and $8 \mathrm{mg} / \mathrm{kg}$ groups, respectively. Tumor volumes were decreased in accordance with the cumulative dose of L-OHP. L-OHP showed higher distribution in tumor tissues at the dose of $8 \mathrm{mg} / \mathrm{kg}$ group than in the other two dose groups.

Correlation between pharmacokinetics and toxicodynamics of $L-O H P$. The pharmacokinetic and toxicodynamic profiles of L-OHP are presented in Figure 5. The $\mathrm{AUC}_{0-\infty}$ of L-OHP after the fourth treatment was strongly correlated with the withdrawal threshold percentage on Day $22\left(\mathrm{R}^{2}=0.9773\right)$. This suggested that the concentration of L-OHP in plasma was associated with the onset of the neuropathy. Therefore, the dose reduction would be controlled before the onset of the mechanical neuropathy. 


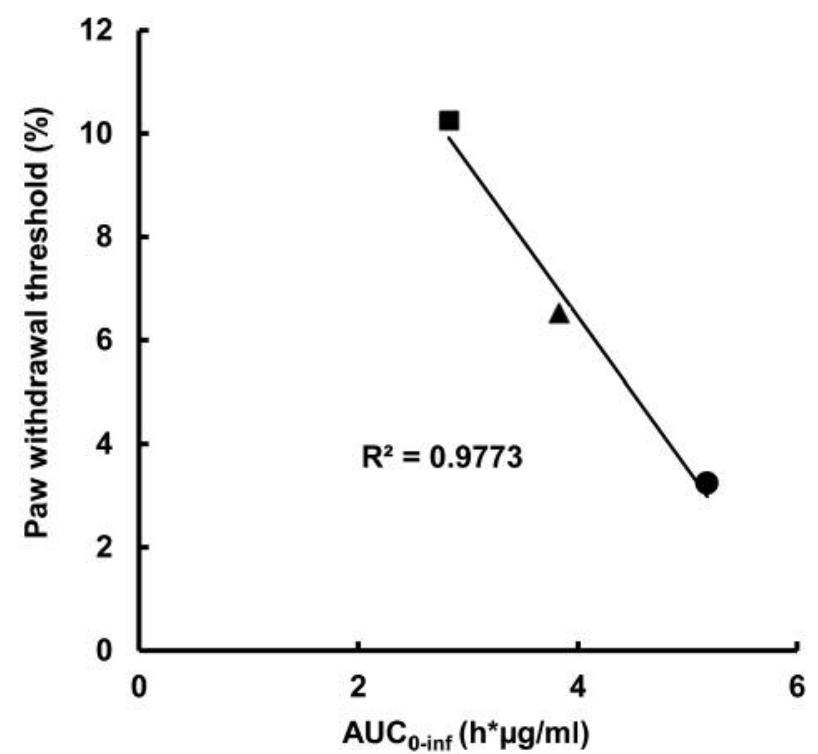

Figure 5. Correlation between the $A U C_{0-\infty}$ of $L-O H P$ and chronic neuropathy on Day 22 as paw withdrawal thresholds, in rats that received $3.0(\mathbf{\square}), 5.0(\mathbf{\Delta})$, and $8.0(\mathbf{\bullet}) \mathrm{mg} / \mathrm{kg}$ doses. Each point represents the mean $\pm S . D$. of four experiments.

\section{Discussion}

Oxaliplatin-induced neuropathy is the main reason for dose reduction, and withdrawal of chemotherapy. Approaches to avoid or reduce these problems can improve the efficacy of cancer chemotherapy. Two different approaches have been proposed to avoid the oxaliplatin-induced neuropathy: a stopand-go approach; and the use of calcium and magnesium infusions. However, neither approach is sufficiently efficient $(5,6)$. Therefore, neuropathy represents a serious barrier to the increase in survival rate in colorectal cancer patients treated with chemotherapy. Sangeetha has reported that the sensory testing is a useful method for the prediction of chronic neuropathy (19) and Tanishima et al. (20) have reported that hyperacute peripheral neuropathy can be evaluated as a predictor in Cycle 1; however, neither study measured the plasma concentrations of L-OHP. For clinical oncotherapy, it is important to adjust the plasma or serum drug concentration. Our previous study has indicated that there is a correlation between plasma L-OHP concentration and the onset of neuropathy (13). However, the association with the antitumor efficacy was unclear in the pathological conditions of colorectal cancer. Nikanjim (21) has reported population pharmacokinetic analysis, including covariates, for the administered dose and Rieu et al. have also proposed a population pharmacokinetic model of L-OHP in patients with thrombocytopenia (22). These scientists did not consider neurotoxicity in the population pharmacokinetic model. Other researchers have studied the mechanism of oxaliplatin-induced neuropathy in mice, (23) but the pharmacokinetic and toxicodynamic profiles were not simultaneously evaluated in the model animals. In this study, to prevent the onset of neuropathy, the association between the plasma concentration of L-OHP and chronic neuropathy was investigated, including the anticancer effect in colorectal cancer rats.

In the pharmacokinetic study of multiple-dose L-OHP (3, 5 , or $8 \mathrm{mg} / \mathrm{kg}$ ) administration, the L-OHP concentrations in plasma were dose-dependently increased, and significant changes were observed at the dose of $8 \mathrm{mg} / \mathrm{kg}$. The $\mathrm{AUC}_{0-\infty}$ value of L-OHP was increased in the group of $8 \mathrm{mg} / \mathrm{kg}$, but the clearance was not significantly different. It is suggested that repeated administration of L-OHP affects renal function and results in high distribution of L-OHP in tumor tissue, as has also been reported by Charlet et al. (22).

In the study of the neurotoxicity, mechanical allodynia was observed on Day 19 in the highest dose $(8 \mathrm{mg} / \mathrm{kg})$ group, and the extent of the allodynia was increased in a L-OHP dosedependent manner (Figure 2), and with higher plasma concentrations of L-OHP. This was due to the cumulative dose, and was consistent with the report of Alejandro et al. (24). Although there are some reports suggesting that the mechanism of oxaliplatin-induced neuropathy is associated with TRPA1- or STAT3-regulated CXCL12 in the dorsal root ganglion cells $(25,26)$, there was no drastic strategy for oxaliplatin-induced neuropathy (27). Therefore, a methodology for dose adjustment of L-OHP, to prevent disruption of chemotherapy, is expected to be based on the relationship between the plasma concentration of L-OHP and the occurrence of mechanical allodynia. In clinical chemotherapy, maximum tumor shrinkage, minimum adverse effects, and minimal withdrawal symptoms are simultaneously required. That is, the management of the oxaliplatin-induced chronic neuropathy, based on the control of L -OHP concentration may lead to the improvement in the quality of life of patients receiving chemotherapy. Our findings confirmed the association between the $\mathrm{AUC}_{0-\infty}$ value, as an index of L-OHP exposure, and the onset of the mechanical allodynia, with a correlation coefficient of 0.9773 (Figure 5), where the $\mathrm{AUC}_{0-\infty}$ value was estimated from the plasma LOHP concentration $v s$. time curve and was used as the index of the exposure of L-OHP. Based on this result, the pharmacokinetic-toxicodynamic model would help to predict chronic neuropathy from L-OHP concentration. In addition, the antitumor effect was confirmed by the reduction in tumor volume and the distribution of L-OHP in tumor tissue. This treatment was safely performed, whereas a higher frequency of neuropathy (except for chronic neuropathy) was observed at higher doses (Figures 3 and 4).

Recently, a Phase III clinical study has shown that a LOHP-based chemotherapy administered over a 3-month 
schedule was not inferior to a 6-month schedule (28). This is one strategy for continuous regimen cycles of L-OHP based therapy. It is important to balance the effectiveness and the ineffectiveness of the anticancer drug by the repeated administration. Therefore, we propose a management strategy for the oxaliplatin-induced chronic neuropathy based on the pharmacokinetic and toxicodynamic data. Before peripheral neuropathy onset due to the dose and exposure of oxaliplatin, dose reduction of L-OHP is proposed to allow long-term chemotherapy and a beneficial contribution to the long-term prognosis from the perspective of patient risk-benefit. Based on the pharmacokinetic/toxicodynamic (PK/TD) of oxaliplatin in CRC model rats, a clinical PK/TD model could be established to predict the occurrence of oxaliplatin-induced chronic neuropathy (29). When the relationship between animal data and human data has been determined, it is necessary to confirm the association between patient's oxaliplatin blood concentration and the degree of peripheral nerve disorder.

\section{Conclusion}

Our findings in this preliminary study on the success of the chemotherapy regimen contributed useful and valuable information to the establishment of a pharmacokinetictoxicodynamic model. Furthermore, this work revealed the importance of translational studies for the improvement of the clinical outcomes by ensuring appropriate drug treatments.

\section{Conflicts of Interest}

Y. Ito, S. Kobuchi, W. Takesada, and C. Takahashi declare that they have no conflicts of interest.

\section{Funding}

This study was supported by a Grant-in-Aid for Scientific Research (C) from JSPS KAKENHI, Grant Number 15K08085.

\section{Authors' Contributions}

Yukako Ito: Conception and design of this study, drafting of the article and critical revision of the article for important intellectual content; Shinji Kobuchi: Analysis and interpretation of data; Waki Takesada: Collection and assembly of data of mechanical allodynia; Chiharu Takahashi: Collection and assembly of data of pharmacokinetic and tumor tissue samples.

\section{Acknowledgements}

The Authors would like to thank Professor Toshiyuki Sakaeda for his invaluable help and support during the writing of the article. This study would not have been possible without his guidance.

\section{References}

1 André T, Boni C, Mounedji-Boudiaf L, Navarro M, Tabernero J, Hickish T, Topham C, Zaninelli M, Clingan P, Bridgewater J, Tabah-Fisch I and de Gramont A; Multicenter International Study of Oxaliplatin/5-Fluorouracil/Leucovorin in the Adjuvant Treatment of Colon Cancer (MOSAIC) Investigators: Oxaliplatin, fluorouracil, and leucovorin as adjuvant treatment for colon cancer. N Engl J Med 350: 2343-2351, 2004. PMID: 15175436. DOI: $10.1056 /$ NEJMoa032709

2 de Gramont A, Figer A, Seymour M, Homerin M, Hmissi A, Cassidy J, Boni C, Cortes-Funes H, Cervantes A, Freyer G, Papamichael D, Le Bail N, Louvet C, Hendler D, de Braud F, Wilson C, Morvan F and Bonetti A: Leucovorin and fluorouracil with or without oxaliplatin as first-line treatment in advanced colorectal cancer. J Clin Oncol 18: 2938-2947, 2000. PMID: 10944126. DOI: $10.1200 / \mathrm{JCO} .2000 .18 .16 .2938$

3 Weickhardt A, Wells K and Messersmith W: Oxaliplatin-induced neuropathy in colorectal cancer. J Oncol 2011: 201593, 2011. PMID: 22203844. DOI: 10.1155/2011/201593

4 Saif MW and Reardon J: Management of oxaliplatin-induced peripheral neuropathy. Ther Clin Risk Manag 4: 249-258, 2005. PMID: 18360567.

5 Tournigand C, Cervantes A, Figer A, Lledo G, Flesch M, Buyse M, Mineur L, Carola E, Etienne PL, Rivera F, Chirivella I, Perez-Staub N, Louvet C, André T, Tabah-Fisch I and de Gramont A: OPTIMOX1: a randomized study of FOLFOX4 or FOLFOX7 with oxaliplatin in a stop-and-Go fashion in advanced colorectal cancer-a GERCOR study. J Clin Oncol 24: 394-400, 2006. PMID: 16421419. DOI: 10.1200/JCO.2005. 03.0106

6 Grothey A, Nikcevich DA, Sloan JA, Kugler JW, Silberstein PT, Dentchev T, Wender DB, Novotny PJ, Chitaley U, Alberts SR and Loprinzi CL: Intravenous calcium and magnesium for oxaliplatin-induced sensory neurotoxicity in adjuvant colon cancer: NCCTG N04C7. J Clin Oncol 29: 421-427, 2011. PMID: 2118938. DOI: $10.1200 / J C O .2010 .31 .5911$

7 Pasetto LM, D'Andrea MR, Rossia E and Monfardinia S: Oxaliplatin-related neurotoxicity: how and why? Crit Rev Oncol Hematol 59: 159-168, 2006. PMID: 16806962. DOI: 10.1016/ j.critrevonc.2006.01.001

8 Argyriou AA, Polychronopoulos P, Iconomou G, Koutras A, Makatsoris T, Gerolymos MK, Gourzis P, Assimakopoulos K, Kalofonos HP and Chroni E: Incidence and characteristics of peripheral neuropathy during oxaliplatin-based chemotherapy for metastatic colon cancer. Acta Oncol 46: 1131-1137, 2007. PMID: 17851880 . DOI: 10.1080/02841860701355055

9 Cavaletti G, Tredici G, Petruccioli MG, Dondè E, Tredici P, Marmiroli P, Minoia C, Ronchi A, Bayssas M and Etienne GG: Effects of different schedules of oxaliplatin treatment on the peripheral nervous system of the rat. Eur J Cancer 37: 24572463, 2001. PMID: 11720843. DOI: $10.1016 /$ S0959-8049(01) 00300-8.

10 McKeage MJ, Hsu T, Screnci D, Haddad G and Baguley BC: Nucleolar damage correlates with neurotoxicity induced by different platinum drugs. Br J Cancer 85: 1219-1225, 2001. PMID: 11710838. DOI: 10.1054/bjoc.2001.2024

11 Luo FR, Wyrick SD and Chaney SG: Comparative neurotoxicity of oxaliplatin, ormaplatin, and their biotransformation products utilizing a rat dorsal root ganglia in vitro explant culture model. 
Cancer Chemother Pharmacol 44: 29-38, 1999. PMID: 10367746. DOI: $10.1007 / \mathrm{s} 002800050941$

12 Jamieson SM, Liu J, Connor B and McKeage MJ: Oxaliplatin causes selective atrophy of a subpopulation of dorsal root ganglion neurons without inducing cell loss. Cancer Chemother Pharmacol 56: 391-399, 2005. PMID: 15887017. DOI: 10.1007/ s00280-004-0953-4

13 Ito Y, Kobuchi S, Shimizu R and Katsuyama Y: Pharmacokinetic and toxicodynamic evaluation of oxaliplatin-induced neuropathy and hematological toxicity in rats. Cancer Chemother Pharmacol 81: 155-161, 2018. PMID: 29164296. DOI: 10.1007/s00280017-3485-4

14 Onose J, Imai T, Hasumura M, Ueda M and Hirose M: Rapid induction of colorectal tumors in rats initiated with 1,2dimethylhydrazine followed by dextran sodium sulfate treatment. Cancer Lett 198: 145-152, 2003. PMID: 12957352. DOI: $10.1016 / \mathrm{S} 0304-3835(03) 00316-1$

15 Di Cesare Mannelli L, Pacini A, Bonaccini L, Zanardelli M, Mello $\mathrm{T}$ and Ghelardini C: Morphologic features and glial activation in rat oxaliplatin-dependent neuropathic pain. J Pain 14: 1585-1600, 2013. PMID: 24135431. DOI: 10.1016/j.jpain. 2013.08.002

16 Sakurai M, Egashira N, Kawashiri T, Yano T, Ikesue H and Oishi $\mathrm{R}$ : Oxaliplatin-induced neuropathy in the rat: involvement of oxalate in cold hyperalgesia but not mechanical allodynia. Pain 147: 165-174, 2009. PMID: 19782472. DOI: 10.1016/ j.pain.2009.09.003

17 Minakata K, Suzuki M, Nozawa H, Gonmori K, Watanabe K and Suzuki O: Platinum levels in various tissues of a patient who died 181 days after cisplatin overdosing determined by electrospray ionization mass spectrometry. Forensic Toxicol 24 83-87, 2006. DOI: 10.1007/s11419-006-0013-3

18 Argyriou AA, Bruna J, Marmiroli P and Cavaletti G: Chemotherapy-induced peripheral neurotoxicity (CIPN): an update. Crit Rev Oncol Hematol 82: 51-77, 2011. PMID: 21908200. DOI: 10.1016/j.critrevonc.2011.04.012

19 Reddy SM, Vergo MT, Paice JA, Kwon N, Helenowski IB, Benson AB, Mulcahy MF, Nimeiri HS and Harden RN: Quantitative sensory testing at baseline and during cycle 1 oxaliplatin infusion detects subclinical peripheral neuropathy and predicts clinically overt chronic neuropathy in gastrointestinal malignancies. Clin Colorectal Cancer 15: 37-46, 2016. PMID: 26337211. DOI: 10.1016/j.clcc.2015.07.001

20 Tanishima H, Tominaga T, Kimura M, Maeda T, Shirai Y and Horiuchi T: Hyperacute peripheral neuropathy is a predictor of oxaliplatin-induced persistent peripheral neuropathy. Support Care Cancer 25(5): 1383-1389, 2016. PMID: 27921224. DOI: 10.1007/s00520-016-3514-6.

21 Nikanjam M, Stewart CF, Takimoto CH, Synold TW, Beaty O, Fouladi $\mathrm{M}$ and Capparelli EV: Population pharmacokinetic analysis of oxaliplatin in adults and children identifies important covariates for dosing. Cancer Chemother Pharmacol 75: 495503, 2015. PMID: 25557868. DOI: 10.1007/s00280-014-2667-6

22 Chalret du Rieu Q, White-Koning M, Picaud L, Lochon I, Marsili S, Gladieff L, Chatelut E and Ferron G: Population pharmacokinetics of peritoneal, plasma ultrafiltrated and protein-bound oxaliplatin concentrations in patients with disseminated peritoneal cancer after intraperitoneal hyperthermic chemoperfusion of oxaliplatin following cytoreductive surgery: correlation between oxaliplatin exposure and thrombocytopenia. Cancer Chemother Pharmacol 74: 571-582, 2014. PMID: 25053386. DOI: 10.1007/ s00280-014-2525-6

23 Zhao M, Isami K, Nakamura S, Shirakawa H, Nakagawa T and Kaneko S: Acute cold hypersensitivity characteristically induced by oxaliplatin is caused by the enhanced responsiveness of TRPA1 in mice. Mol Pain 28(8): 55, 2012. PMID: 22839205. DOI: $10.1186 / 1744-8069-8-55$

24 Alejandro LM, Behrendt CE, Chen K, Openshaw H and Shibata $\mathrm{S}$ : Predicting acute and persistent neuropathy associated with oxaliplatin. Am J Clin Oncol 36(4): 331-337, 2013. PMID: 22547012. DOI: $10.1097 / C O C .0 B 013 E 318246 B 50 D$

25 Park JH, Chae J, Roh K, Kil EJ, Lee M, Auh CK, Lee MA, Yeom $\mathrm{CH}$ and Lee S: Oxaliplatin-induced peripheral neuropathy via TRPA1 stimulation in mice dorsal root ganglion is correlated with aluminum accumulation. PLoS One 10(4): e0124875, 2015. PMID: 25928068. DOI: 10.1371/journal.pone.0124875. eCollection 2015

26 Li YY, Li H, Liu ZL, Li Q, Qiu HW, Zeng LJ, Yang W, Zhang XZ and Li ZY: Activation of STAT3-mediated CXCL12 upregulation in the dorsal root ganglion contributes to oxaliplatininduced chronic pain. Mol Pain 13: 1744806917747425, 2017. PMID: 29166835. DOI: 10.1177/1744806917747425

27 Hershman DL, Lacchetti C, Dworkin RH, Lavoie Smith EM, Bleeker J, Cavaletti G, Chauhan C, Gavin P, Lavino A, Lustberg MB, Paice J, Schneider B, Smith ML, Smith T, Terstriep S, Wagner-Johnston N, Bak K and Loprinzi CL: Prevention and management of chemotherapy-induced peripheral neuropathy in survivors of adult cancers: American Society of Clinical Oncology clinical practice guideline. J Clin Oncol 32: 19411967, 2015. PMID: 24733808. DOI: 10.1200/JCO.2013.54.0914

28 André T, Vernerey D, Mineur L, Bennouna J, Desrame J, Faroux R, Fratte S, Hug de Larauze M, Paget-Bailly S, Chibaudel B, Bez J, Dauba J, Louvet C, Lepere C, Dupuis O, Becouarn Y, Mabro M, Egreteau J, Bouche O, Deplanque G, Ychou M, Galais MP, Ghiringhelli F, Dourthe LM, Bachet JB, Khalil A, Bonnetain F, de Gramont A and Taieb $\mathrm{J}$; for PRODIGE investigators, GERCOR, Fédération Française de Cancérologie Digestive, and UNICANCER: Three versus 6 months of oxaliplatin-based adjuvant chemotherapy for patients with stage III colon cancer: disease-free survival results from a randomized, open-label, international duration evaluation of adjuvant (IDEA) France, phase III trial. J Clin Oncol 36(15): 1469-1477, 2018. PMID: 29620995. DOI: 10.1200/JCO.2017.76.0355

29 Puchalski TA, Krzyzanski W, Blum RA and Jusko WJ: Pharmacodynamic modeling of lansoprazole using an indirect irreversible response model. J Clin Pharmacol 41(3): 251-258, 2001. PMID: 11269565. DOI: 10.1177/00912700122010069

Received April 26, 2019

Revised June 21, 2019

Accepted June 24, 2019 